\section{Sistema Único de Saúde e políticas públicas: atendimento psicológico à mulher na menopausa no Distrito Federal, Brasil}

\author{
The Unified National Health System and public \\ policies: psychological care for menopausal \\ women in the Federal District, Brazil
}

1 Política Nacional de Humanização, Ministério da Saúde, Brasília, Brasil.

2 Instituto de Psicologia.

Universidade de Brasília, Brasília, Brasil.

3 Instituto Municipal

de Assistência à Saúde Juliano Moreira,

Rio de Janeiro, Brasil.

Correspondência

M. E. Mori

Política Nacional

de Humanização,

Ministério da Saúde.

SHIN QL 01, conjunto 02,

casa 15, Brasília, DF

71505-025, Brasil.

beth.mori@gmail.com
Maria Elizabeth Mori ${ }^{1}$

Vera Lúcia Decnop Coelho ${ }^{2}$

Renata da Costa Netto Estrella 3

O número de mulheres vivendo em situação de pobreza no mundo é maior que o de homens. Elas, em geral, trabalham mais horas do que eles. E mais. Metade do tempo das mulheres é gasto em atividades não remuneradas - e diríamos, pouco valorizadas socialmente. Com isso, diminui-se o acesso das mulheres a bens, inclusive aos serviços de saúde 1 , foco do presente trabalho.

Assim, estudos que problematizam questões femininas e a saúde da mulher contribuem para o reconhecimento de seu valor e para a superação de preconceitos que ainda atingem a mulher em seu cotidiano. Para se pensar a saúde da mulher e a elaboração de políticas que contemplem uma visão mais abrangente de saúde, a perspectiva de gênero é essencial. "Gênero se refere ao conjunto de relações, atributos, papéis, crenças e atitudes que definem o ser homem ou mulher" 2 (p. 16). As relações de gênero tendem a ser desiguais, refletindo-se em leis, políticas, atitudes e comportamentos das pessoas.

Esta desigualdade atinge particularmente as mulheres que se defrontam com o envelhecimento, determinado não apenas pela idade cronológica, mas também por condições subjetivas e sociais ${ }^{3}$. As mudanças corporais presentes na meia-idade, período que se estende aproximadamente dos 40 aos 60 anos 4 , impactam a auto-imagem feminina e potencializam um sofrer psicológico, segundo a visão de cada cultura em relação à mulher que envelhece 5 . 
Buscou-se investigar a situação de atendimento psicológico à mulher de meia-idade na rede pública de saúde do Distrito Federal. Este trabalho é parte de pesquisa teórico-clínica realizada a partir de demanda de atendimento psicológico às mulheres que participam do Programa de Climatério da Policlínica de Taguatinga, da rede pública de saúde 6 . Voltaremos a essa questão mais adiante.

Para isso, discute-se inicialmente a noção de saúde, e mais especificamente, a da mulher. A seguir, comentam-se aspectos biopsicossociais da meia-idade feminina e menopausa, e como a intervenção psicológica se insere neste contexto de vida. A evolução da atenção à saúde da mulher, ao longo do século XX, com a criação da Política Nacional de Atenção Integral à Saúde da Mulher, do Ministério da Saúde 7, é brevemente apresentada no tópico seguinte. Finalmente, discute-se o resultado de levantamento sobre o atendimento psicológico à mulher de meia-idade na rede pública do Distrito Federal.

\section{A saúde da mulher}

Em 1948, a Organização Mundial da Saúde (OMS) definiu saúde não apenas como ausência de doença ou enfermidade, mas como um bemestar físico, psíquico e social. No entanto, apesar de multidimensional este conceito ainda se baseia num modelo biomédico ${ }^{8}$. Mais recentemente, a OMS ampliou esta definição, reconhecendo os laços entre as pessoas e o ambiente sócio-cultural. Saúde é então concebida como " a habilidade de identificar e realizar aspirações, satisfazer necessidades, e de mudar ou interagir com o meio ambiente. Logo, saúde é um recurso para a vida diária, não o objetivo de viver. Saúde é um conceito positivo enfatizando os recursos pessoais e sociais, assim como as capacidades físicas" 8 (p. 167).

Concepção semelhante sobre saúde é apresentada por van der Kwaak (1991, apud Galvão 8, p. 170): "um modo de bem-estar total, não determinado somente por fatores fisiológicos, mas também por efeitos do trabalho, nutrição, estresse, guerra, migração, entre outros". Daí a importância do planejamento e a disseminação de políticas públicas no Brasil, pois ainda persiste "um modelo cruel de desigualdades históricas internas que apontam para as diferentes oportunidades e restrições da população, segundo os diferentes grupos sociais, gênero, cor e regiões de residência" 9 (p. 25).

A evolução dos conceitos sobre saúde da mulher ao longo das últimas décadas merece aqui um breve comentário. Saúde materna, saúde reprodutiva e saúde da mulher são expressões que apontam para discussões conceituais. Da primeira à terceira pode-se perceber um avanço no que diz respeito à condição feminina. Falar da saúde da mulher significa atentar para todo o contexto psicossocial em que esta se insere. Isto inclui aspectos relativos à enfermidade, doença, bem-estar, assim como às atividades de prevenção, diagnóstico, cuidados e cura. A referência canadense, em relação à saúde da mulher, é representativa de um conceito integral e amplo: "A saúde da mulher envolve aspectos emocionais, sociais e seu bem-estar físico e é determinada por um contexto político, cultural e econômico da vida das mulheres, assim como biológico. Essa ampla definição reconhece a validade das experiências das mulheres, suas opiniões sobre saúde e suas experiências de saúde. Cada mulher deveria ter oportunidade de alcançar e manter sua saúde, tal como definida por ela própria, no seu mais alto potencial" (Women's Health Interschool Curriculum Committee, 1995, apud Galvão 8; p. 173).

As mulheres costumam ser vistas como usuárias passivas e não como protagonistas da própria história, capazes de articular prioridades e tomar decisões. Daí a importância das vozes femininas na definição de suas necessidades e no desenho de políticas e programas 10 . Isto vai na direção do conceito de clínica ampliada, que "visa produzir saúde e aumentar a autonomia do sujeito, da família e da comunidade" 11 (p. 44-5).

Indicadores sociais 12 mostram as diferenças enfrentadas por homens e mulheres em suas trajetórias de vida. Menor crescimento populacional e transformações nas estruturas por idade e sexo vêm ocorrendo nas últimas décadas. O ciclo vital vem se modificando e o fenômeno da longevidade tem forçado a criação de novos estágios de desenvolvimento. A adolescência tem se prolongado, adiando o início da vida adulta. Homens e mulheres experienciam situações diversas das que seus pais e avós viveram. Além do aumento da expectativa de vida, mudanças na sexualidade e reprodução, nas relações de gênero, nos processos de subjetivação e em novas tecnologias de saúde estão ocorrendo. Tais transformações necessitam ser contempladas pelas políticas públicas de saúde.

Tais políticas devem considerar fenômenos como: precocidade da menarca e do início das relações sexuais entre jovens; meios contraceptivos que desvinculam sexo de reprodução; aumento da incidência de gravidez na adolescência e tardia (depois dos quarenta, devido às tecnologias que garantem a fertilização mesmo 
após a menopausa); jovens adultos solteiros e mesmo divorciados moram com os pais; homens e mulheres coabitam por mais tempo antes de formalizarem uma união; divórcios e recasamentos promovem rearranjos familiares 13 . Idosos convivem com doenças crônico-degenerativas com amplas repercussões sobre a família. Por outro lado, aqueles que possuem uma vida saudável na velhice enfrentam maiores desafios para sua inserção social 14 .

$\mathrm{Na}$ interpretação desses processos de mudança é importante destacar a permanência da assimetria nas relações de gênero, desfavorável à mulher, presente, por exemplo, no campo da política, do trabalho, da sexualidade. É na violência contra a mulher, entretanto, que a dissimetria de gênero transparece em sua radicalidade. Estudos sobre violência sexual, violência doméstica, assédio moral e sexual apontam o impacto deste fenômeno na saúde mental da mulher 15,16,17,18. A fala de mulheres nos grupos de atendimento psicológico realizados em serviços de saúde por pesquisadoras-psicólogas 6, 19,20,21 evidencia a presença de relações marcadas pela violência, ao longo do ciclo vital. Esta realidade sinaliza a importância da escuta psicológica no contexto público de atendimento à mulher.

\section{Meia-idade, menopausa e escuta psicológica}

A meia-idade compreende o período entre 40 a 60 anos, aproximadamente. No entanto, a idade cronológica constitui um critério relativo e insuficiente para a compreensão desta fase da vida, considerada crítica por diferentes autores 4,22,23,24,25, pelas transformações físicas, psíquicas e sociais que aí se intercruzam 26. As mulheres enfrentam mudanças significativas nesses anos intermediários da vida, onde tem lugar a menopausa.

Fisiologicamente, menopausa se refere à cessação definitiva da ovulação. No entanto, a OMS recomenda que o termo seja utilizado para designar o processo como um todo, e não apenas o cessar do fluxo menstrual. Fenômeno natural na vida da mulher, a menopausa tem sido freqüentemente tratada como doença, reduzindo-se sua complexidade à queda dos níveis hormonais. Ondas de calor, sudorese, secura vaginal, insônia, irritabilidade, dor de cabeça, ansiedade e sintomas depressivos, entre outras queixas, podem estar presentes 27. Entretanto, as mulheres vivenciam estas mudanças de maneira diversificada 28,29 , o que é reafirmado por estudos sociais e transculturais 30,31 .
O corpo feminino se transforma. Rugas, perda da elasticidade da pele e da flexibilidade corporal, embranquecimento dos cabelos e ganho de peso sinalizam o inevitável processo de envelhecimento, impactando a auto-imagem da mulher. Vivendo em sociedades que cultuam a juventude, a beleza e a saúde 5 e que desvalorizam o idoso 32 , é sem dúvida doloroso para a mulher enfrentar o seu envelhecer. Goldfarb 33 se refere ao "espelho negativo" - estranheza ante a própria imagem que a mulher de meia-idade vê diante do espelho, prenunciando a velhice sob o ponto de vista estético.

Relações conjugais e familiares são igualmente afetadas. Relacionamentos afetivos desgastados podem implicar em separação ou sofrimento conjugal. As mães confrontam-se com filhos que passam da adolescência para a fase adulto-jovem, podendo enfrentar: saída ou não de casa, gravidez precoce, abuso de drogas lícitas e ilícitas, doenças sexualmente transmissíveis e violência. A mulher de meia-idade é, assim, convocada a assumir funções que a sobrecarregam 34. A aposentadoria pode afetar a mulher em sua identidade e relações. Pais idosos demandam cuidados que envolvem esforços econômicos e psíquicos. $\mathrm{O}$ adoecimento e morte destes potencializa o contato da mulher com a própria fragilidade e finitude 6 .

Margis \& Cordioli 4 concluíram que essas transformações instauram na mulher de meiaidade um processo de reavaliação psíquica envolvendo tarefas como: aceitação do corpo que envelhece; aceitação da limitação do tempo e da morte; revisão dos papéis sociais exercidos nos relacionamentos (cônjuge, filhos, pais e outros membros da sociedade), com a inserção em novas posições sociais; apreensão de novas habilidades e sentidos para a vida; e preparação para a velhice por meio de estratégias de prevenção e promoção de saúde, incluindo vínculos sociais.

O trabalho clínico nos mostra que a mulher deseja e precisa falar sobre conflitos que se manifestam, ressurgem ou se intensificam na meia-idade e na menopausa. A Consulta de Enfermagem, realizada como parte do Programa do Climatério da Policlínica de Taguatinga, Distrito Federal, confirma esta perspectiva. Além das queixas físicas relativas à menopausa, trajetórias de vida marcadas por violências sexuais e físicas, conflitos familiares, situações de abandono e de negligência, entre outras questões, são expressas muitas vezes pela primeira vez nessa Consulta. Tais vivências podem se manifestar em sintomas/transtornos, como depressão e ansiedade 6 . A intervenção psicológica grupal com mulheres na meia-idade tem de- 
monstrado que compartilhar histórias de vida com outras que atravessam a mesma etapa de vida possibilita a busca de sentido para tantas transformações e desafios 35,36,37.

A presença de psicólogos na rede pública de saúde do Distrito Federal é igualmente demandada por profissionais de saúde. Entrevistas realizadas com ginecologista, psiquiatra, enfermeiras e gestor da Secretaria de Estado de Saúde do Distrito Federal (SES/DF) apontaram que a escuta psicológica deve integrar uma proposta de atenção integral à saúde da mulher de meia-idade 6 .

\section{Políticas públicas e a saúde da mulher brasileira}

Nas primeiras décadas do século XX a saúde da mulher passou a fazer parte das políticas públicas de saúde. Nas décadas de 1930, 1940 e 1950 os programas materno-infantis contribuíam para uma visão restrita da mulher como mãe e "dona de casa". A saúde da mulher passa a ser fonte de preocupação de diversos países devido ao crescimento acelerado da população mundial. No Brasil, programas de "controle da natalidade" disseminaram-se no final da década de 1970.

Os objetivos demográficos foram os grandes norteadores destes programas, voltados à redução da fecundidade. As atividades de controle da natalidade expandiram-se. Como afirmam Díaz \& Díaz 10 (p. 209), “as ações visavam recrutar novas usuárias de métodos de alta eficácia, sem dar a devida importância às necessidades ou preferências das mulheres". A melhoria da saúde e da qualidade de vida populacional ficava relegada a segundo plano. Problemas advindos da adoção desses programas levaram cientistas e movimentos feministas a manifestarem sua insatisfação, ocasionando revisões das políticas internacionais em saúde da mulher. Entretanto, a ênfase se manteve nos aspectos reprodutivos. A mulher que merecia atenção do Estado era aquela que se encontrava no período fértil.

A partir da década de 1960, movimentos feministas contribuíram para trazer ao espaço público questões até então tratadas como de âmbito privado. O slogan Nosso Corpo Nos Pertence, refletia a luta das mulheres pela autonomia individual em detrimento das formas de subordinação feminina, já que o caráter de objeto do corpo feminino é a face visível da subjugação das mulheres 38 . Esta palavra de ordem percorreu o mundo na década de 1970, capturando a imaginação das mulheres nos mais di- versos continentes e motivando "pequenas rebeliões e demandas públicas” 39 (p. 72).

A produção feminista das décadas de 70 e 80 do século XX pontuou a sexualidade como um direito. A tomada de consciência sobre si, como sujeitos, foi fundamental para situar a repressão à sexualidade como uma estratégia de dominação. A Conferência Internacional sobre População e Desenvolvimento, realizada no Cairo, Egito, em 1994, e a IV Conferência Mundial sobre a Mulher, realizada em Pequim, China, 1995, procuraram fortalecer esse processo num movimento com marcas mundiais.

Formiga Filho 40 enfatiza que o engajamento das mulheres na luta pelos seus direitos e por melhores condições de vida impulsionou as primeiras medidas oficiais do Ministério da Saúde. Apesar de engessado nos governos militares, o movimento feminista reorganizou-se, abrindo debates que denunciavam a precariedade da saúde da mulher brasileira.

A participação feminina foi intensa na discussão sobre a saúde da mulher, durante a década de 1980. Desde então, uma das principais bandeiras tem sido, segundo Ávila \& Corrêa 39 (p. 73-4), “desfazer o lugar do corpo (da anatomia) como destino (...) de romper a lógica complexa de apropriação e subordinação do corpo feminino às definições de ordem privada e pública". Assim, o tema da saúde sobressaiu-se no cenário feminista.

Nesse contexto, criou-se o Conselho Nacional dos Direitos da Mulher (CNDM), a Comissão Nacional de Estudos dos Direitos da Reprodução Humana, no Ministério da Saúde, e o PAISM (Programa de Assistência Integral à Saúde da Mulher) em 1984. Este programa acabou canalizando grupos autônomos envolvidos com a saúde da mulher, no que diz respeito à mobilização, organização e representação política, além da produção e difusão de informação e de conhecimento 39.

Segundo Formiga Filho 40, o PAISM foi importante para a área da saúde brasileira, em especial à saúde da mulher. Esta área tem sido fonte de lucros de alguns grupos ou instituições que, de maneira inescrupulosa, atuam com interesses primordialmente financeiros. O Programa contemplava estratégias que abordavam a saúde da mulher em todas as etapas do ciclo vital. Ações educativas, preventivas, de diagnóstico, tratamento ou recuperação com vistas à melhoria da saúde da população feminina estavam previstas. Dentre as ações regulamentadas e normatizadas pelo PAISM encontrava-se a assistência ao climatério.

Autores como Pinotti et al. (1990, apud Galvão 8), Osis (1998, apud Galvão 8) e Costa (1999, 
apud Galvão ${ }^{8)}$ sugerem que o PAISM não foi adequadamente implementado no Brasil, apontando o distanciamento entre concepção e prática. Segundo os autores, a efetividade de um programa com tal envergadura depende de fatores políticos, econômicos, culturais e sociais. Daí a importância de um controle social eficaz, com o envolvimento contínuo de grupos de mulheres e instituições.

Cabe comentar brevemente o estado atual das políticas públicas da saúde da mulher, lançadas pelo Ministério da Saúde 2. Dentre as Leis e Portarias editadas no período de 1996 a 2000 os seguintes temas são relativos à mulher: planejamento familiar, notificação compulsória de violência contra a mulher, humanização no pré-natal e nascimento e atendimento aos casos de aborto ilegal. Infelizmente, nota-se nesse conjunto de leis uma ausência importante: a saúde mental.

Assim, a Política Nacional de Atenção à Saúde da Mulher - Princípios e Diretrizes 7 representa um grande avanço. A Síntese das Diretrizes para a Política de Atenção Integral à Saúde da Mulher: 2004-2007 1 (p. 77) considera, "num enfoque de gênero, a evolução das políticas, a situação sócio-demográfica e o diagnóstico da saúde da mulher no Brasil". Incorporam-se a integralidade e a promoção da saúde como princípios norteadores, buscando consolidar os avanços no campo dos direitos sexuais e direitos reprodutivos. A melhoria da atenção obstétrica, o planejamento familiar, a atenção ao abortamento, o controle à violência doméstica e sexual, a prevenção e tratamento das DST/HIV/ AIDS, de doenças crônico-degenerativas e do câncer ginecológico são alvos dessa política.

As diretrizes incluem, no seu "plano de ação 2004-2007” 41, grupos até então não contemplados: trabalhadoras rurais, mulheres negras, mulheres na menopausa e na terceira idade, lésbicas, indígenas, presidiárias, mulheres com deficiências ou transtornos mentais. Esta política é destinada à população feminina acima de dez anos - mais de 70 milhões de brasileiras, majoritariamente usuárias do Sistema Único de Saúde (SUS).

Apesar do inegável avanço, é essencial questionar a real implementação desses princípios nos municípios e estados brasileiros. Mais ainda. A efetivação desta política depende igualmente dos gestores das unidades de saúde e dos profissionais que lidam diretamente com o público feminino. O presente estudo se insere nesse contexto, buscando investigar o atendimento psicológico no serviço público de saúde do Distrito Federal à mulher de meia-idade.

\section{Atendimento à mulher de meia-idade na rede pública de saúde do Distrito Federal}

O levantamento efetuado por Mori 6 na rede pública de saúde do Distrito Federal mostrou que existiam poucas ações de promoção à saúde da mulher de meia-idade. Geralmente, apenas o atendimento ambulatorial ginecológico, com vistas à prevenção de câncer de útero e de mama, era oferecido a esta população.

Procurou-se identificar os centros de saúde e os hospitais regionais do Distrito Federal que ofereciam atendimento psicológico à mulher de meia-idade. Dos 32 centros de saúde consultados na época - abrangendo Lago Sul e Norte, Cruzeiro, Ceilândia, Sobradinho, Gama, Taguatinga, Planaltina, Samambaia, Candangolândia, Riacho Fundo 1 e Plano Piloto - apenas os de n. 14 (Cruzeiro Velho), 02 (Sobradinho) e 01 (Plano Piloto) promoviam, além da consulta com o ginecologista, palestras educativas semanais ou quinzenais, acerca da menopausa.

Dos Hospitais Regionais investigados - Ceilândia, Sobradinho, Gama, Taguatinga, Planaltina, Samambaia e Plano Piloto - apenas o Hospital Regional da Asa Sul (HRAS) e a Policlínica de Taguatinga realizavam atividades voltadas à promoção de saúde da mulher da meia-idade, os chamados Programas de Climatério. Cabe enfatizar que a existência desses programas se devia exclusivamente às iniciativas individuais de médicos e enfermeiras. Estes implementavam, além dos serviços preventivos orientados pelas políticas de saúde da SES/DF, palestras educativas semanais a respeito do climatério/ menopausa e palestras mensais com especialistas.

Além disso, o HRAS, que contava com seis psicólogos no quadro de pessoal, disponibilizava uma psicóloga para realizar, eventualmente, atendimento individualizado à mulher em casos considerados graves. Já a Policlínica de Taguatinga, que não contava com psicólogos contratados, realizava a consulta de enfermagem, visando criar um espaço de escuta para acolher a problemática trazida pela mulher. Neste contexto se inseriu a solicitação de colaboração de pesquisadoras-psicólogas do Departamento de Psicologia Clínica, Universidade de Brasília para ampliar a compreensão sobre a complexidade do fenômeno menopausa e realizar intervenção psicológica.

Esses resultados nos levaram a questionar: faltam recursos financeiros para a saúde da mulher de meia-idade? Ou falta sensibilidade para a alocação de verbas em programas de promoção de sua saúde? E mais, falta compreensão 
sobre a importância do atendimento psicológico na linha de cuidado a essa mulher? Desconhecem-se os efeitos dos conflitos psíquicos no corpo? Ou falta (re)conhecimento do trabalho realizado pelo profissional de psicologia? Estas foram as principais questões que nos fizeram procurar a SES/DF.

Assim, entrevistou-se uma gestora - médica e especialista em administração hospitalar que na ocasião atuava na Diretoria de Promoção e Assistência à Saúde. Nesta Diretoria encontravam-se todos os programas da área básica da comunidade: mulher, criança, adulto, idoso, triagem neonatal, controle de câncer de útero e de mama, controle da dengue e da cólera e demais epidemiologias.

Segundo nossa entrevistada, as políticas e os programas federais de saúde para a mulher visam primordialmente reduzir índices de mortalidade, focalizando ações nos grupos de maior risco: criança e mulher na fase reprodutiva. À medida que se começou a obter melhores indicadores nessa área, o governo ampliou sua atuação para a prevenção de câncer e de outras patologias, como hipertensão e diabetes.

De acordo com a gestora, no que diz respeito à saúde da mulher no Brasil, trabalha-se com taxas de riscos, cujos investimentos e indicadores estão voltados mais para a fase reprodutiva. Fora desse período, a preocupação é com doenças. Persiste a idéia de que cuidar da saúde é evitar a morte, e não, promoção da saúde.

Neste sentido, tem se compreendido que os poucos programas de climatério se constituíram a partir da iniciativa de profissionais da área. Esses programas não fazem parte das estratégias do Ministério da Saúde e nem das secretarias de saúde dos Estados e do Distrito Federal. A gestora confirmou que são poucos os lugares na rede pública que oferecem ações educativas em relação à meia-idade feminina. Os hospitais que as realizam têm no seu quadro de pessoal profissionais que fizeram alguma especialização nessa área e usam parte do seu horário semanal para tais ações.

Entendemos que um país com restrições financeiras, como é o caso do Brasil, necessita priorizar áreas de alocação de recursos. No entanto, essas iniciativas dos profissionais contribuem para a promoção da saúde e prevenção de doenças. Ao mesmo tempo, mostram que é fundamental investir na prevenção e promoção da saúde integral e não apenas na medicalização. Nas ações psicológicas não se utilizam remédios. Dessa maneira, os investimentos financeiros estariam voltados para a criação de empregos. Ganharia, em primeiro lugar, a clientela assistida. Além disso, a categoria profissio- nal de psicólogos seria beneficiada, tendo em vista a expansão de seu campo de atuação no âmbito da saúde.

Atualmente quando comparamos o número da dotação prevista pela SES/DF - realizada pelas áreas técnicas e especificada pelas Leis $n$. 3.323 e $n$. 3.320 , de 2004 - para os profissionais de medicina, enfermagem, psicologia e assistência social evidencia-se o pouco prestígio dos psicólogos nas ações de saúde do Distrito Federal. Vejamos: 5.138 vagas estão destinadas aos médicos, 1.410 a enfermeiros, 205 a assistentes sociais e 76 para psicólogos. Destes 76, segundo a Coordenadoria de Saúde Mental (COSAM), a rede de assistência conta apenas com 51 psicólogos. Conclui-se, portanto, que o quadro de pessoal da SES/DF para o profissional de psicologia está totalmente defasado considerando as necessidades de uma população de dois milhões de pessoas, apenas no Distrito Federal, fora as cidades do entorno.

Para a gestora entrevistada, o psicólogo tem muito a contribuir, principalmente nos trabalhos preventivos e de promoção da saúde. Cita, como exemplo de atuação possível, o trabalho voltado para a saúde mental da mulher de meiaidade, tendo em vista que esta foi "massacrada”, sobrecarregada ao longo de seu ciclo vital.

A entrevistada aponta, ainda, o preconceito que se tem em relação ao envelhecimento feminino, situação que vem se modificando, segundo ela. A mulher está gradativamente se emancipando, tornando-se mais ciente de seus direitos e lutando por eles. Infelizmente sabemos que muitas mulheres, nessa faixa etária, ainda não conseguiram tal emancipação. Finalmente, ao apontar o papel do psicólogo, a entrevistada lembrou o campo de atuação da Psicologia da Saúde. Esta se caracteriza, de acordo com Seidl \& Costa Jr. 42 (p. 27), como "uma área de conhecimento voltada à compreensão da influência de variáveis de natureza psicológica sobre processos de manutenção de estados de saúde de indivíduos ou grupos sociais, bem como sobre processos de geração de doença e estratégias de intervenção que auxiliem os indivíduos a manter-se saudáveis ou a enfrentar processos patológicos".

Tais considerações nos remetem a uma questão, que se refere ao reconhecimento pelas instâncias públicas de saúde - nos níveis federal, estadual e municipal - de que a saúde mental é parte integrante do bem-estar dos cidadãos; o psicólogo deve, portanto, ter lugar junto a médicos, enfermeiros e demais profissionais, nos projetos e programas multidisciplinares de saúde dos governos. 


\section{Considerações finais}

O estudo buscou investigar a situação do atendimento psicológico à mulher de meia-idade na rede pública de saúde do Distrito Federal. Para tal, realizou-se um levantamento em unidades de assistência da SES/DF.

Conclui-se que a atenção integral à mulher de meia-idade, incluindo o trabalho psicológico, ainda não é parte integrante das políticas públicas de saúde do Distrito Federal. Na rede hospitalar, mais especificamente nos hospitais regionais e policlínica, percebe-se que o profissional da psicologia está ausente dos poucos trabalhos desenvolvidos com a população feminina nessa faixa etária. Mulheres que necessitam de tratamento psicológico não encontram, ainda, respostas nesses serviços de saúde.

Os poucos programas de atendimento à meia-idade feminina foram elaborados e implementados por profissionais da área médica e de enfermagem, que por razão pessoal estão interessados em colocar seus saberes a serviço deste público-alvo. As ações implementadas por estes profissionais limitam-se à consulta ginecológica e palestras educativas periódicas acerca da menopausa/climatério. Assim, da mesma forma que se inicia a oferta de tais serviços, estes podem ser extintos.

No caso da Policlínica de Taguatinga, cidade satélite do Distrito Federal, as usuárias do Programa de Climatério também contam com a consulta de enfermagem, atividade implantada pela enfermeira sanitarista Euzira Maria do Espírito Santo, comprometida com a assistência integral à mulher de meia-idade. $\mathrm{O}$ atendimento, a partir de 2001, passou a contar com o trabalho de escuta psicológica grupal, oferecido por pesquisadoras da Universidade de Brasília 43.

Estas profissionais, em conjunto com alunos da graduação e pós-graduação do Instituto de Psicologia (Departamento de Psicologia Clínica, Universidade de Brasília), têm ocupado um espaço de trabalho psicológico negligen- ciado por instituições de saúde. A ausência de programas, ações e serviços à mulher de meiaidade denota desatenção aos princípios fundamentais do SUS: integralidade, universalidade e eqüidade. Ações psicológicas, como a desenvolvida por este grupo, são formas de reduzir um dos problemas que o SUS tem enfrentado: "precária interação das equipes e despreparo para lidar com a dimensão subjetiva nas práticas de atenção" 11 (p. 15).

Cabe ainda reafirmar que a disparidade entre os números de profissionais de saúde, apresentada anteriormente, demonstra que o trabalho do psicólogo ainda não tem sua importância reconhecida nesse contexto. Na SES/DF não existe, até o momento, uma coordenação de psicologia. Assim, a definição do número de psicólogos que deve compor o quadro de pessoal da rede hospitalar não conta com a participação de um representante da categoria. A isso vem somar-se outra diferença entre profissionais de saúde do Distrito Federal, que é a da jornada de trabalho. Na rede pública do Distrito Federal, em contraste com as 20 horas semanais do médico e do odontólogo, o enfermeiro trabalha 24 horas e o psicólogo, 30 horas.

Concluímos que as políticas públicas de saúde ainda não reconhecem a especificidade da saúde da mulher de meia-idade, tendo em vista as intensas transformações potencializadas pela menopausa e pelo inevitável processo de envelhecimento.

As dimensões biopsicossociais da meiaidade feminina apontam para uma complexidade que necessita do reconhecimento dos gestores de saúde, na formulação de políticas públicas. A assistência à mulher, que inclua atendimento psicológico, não pode depender apenas da iniciativa pessoal de médicos, enfermeiras e assistentes sociais. Entrevistas realizadas por Mori 6 apontam que estes especialistas, em seu trabalho cotidiano, se dão conta de uma lacuna do atendimento integral - a escuta psicológica - pois, se defrontam com questões que extrapolam sua possibilidade de intervenção. 


\section{Resumo}

Objetivou-se investigar a situação de atendimento psicológico à mulher de meia-idade, na rede pública de saúde do Distrito Federal, Brasil. Discutiu-se a saúde da mulher, mais especificamente, daquela que se encontra no período da menopausa e seu lugar nas atuais políticas públicas. Levantamento realizado na rede pública apontou a existência de poucas intervenções psicológicas destinadas à mulher nesta fase do ciclo vital. Em geral, apenas o atendimento ambulatorial ginecológico era oferecido. Em nenhuma das unidades de saúde pesquisadas existiam psicólogos no quadro de pessoal, cujo trabalho fosse dedicado especificamente à mulher na meia-idade. Concluiu-se que esta etapa da vida feminina não tem sido contemplada com assistência psicológica, negligenciando os princípios fundamentais do SUS. O estudo reafirma a necessidade de essa mulher ter acesso ao atendimento integral de sua saúde, incluindo uma escuta psicológica dos conflitos relacionados às dimensões biológicas, psíquicas e sócio-culturais do processo de envelhecimento. Esta escuta especializada pode contribuir para a elaboração da maturidade feminina.

Menopausa; Saúde da Mulher; Política de Saúde

\section{Referências}

1. Ministério da Saúde. Síntese das diretrizes para a política de atenção integral à saúde da mulher 2004 a 2007. In: Ministério da Saúde, organizador. 2004: ano da mulher. Brasília: Ministério da Saúde; 2004. p. 77-82. (Série E. Legislação de saúde).

2. Ministério da Saúde, organizador. 2004: ano da mulher. Brasília: Ministério da Saúde; 2004. (Série E. Legislação de saúde).

3. Sanches M, Roel I. El processo de envejecimiento en la mujer. Revista Tiempo 2001; 8. http://www. psicomundo.com/tiempo8 (acessado em 21/Fev/ 2001).

4. Margis R, Cordioli AV. Idade adulta: meia-idade. In: Elzirk CL, Kapczinski F, Bassols MAS, organizadores. Ciclo de vida humana: uma perspectiva psicodinâmica. Porto Alegre: Artmed Editora; 2001. p. 159-67.

5. Del Priore M. Corpo a corpo com a mulher: pequena história das transformações do corpo feminino no Brasil. São Paulo: Editora Senac; 2000. (Série Ponto Futuro).

6. Mori ME. A vida ou vida: a escuta psicológica e a saúde da mulher de meia-idade [Dissertação de Mestrado]. Brasília: Instituto de Psicologia, Universidade de Brasília; 2002.

7. Ministério da Saúde. Política Nacional de Atenção Integral à Saúde da Mulher: princípios e diretrizes. Brasília: Ministério da Saúde; 2004.

\section{Colaboradores}

M. E. Mori participou da redação do artigo. V. L. D. Coelho contribuiu na revisão do artigo. R. C. N. Estrella colaborou como revisora do texto.
8. Galvão L. Saúde sexual e reprodutiva, saúde da mulher e saúde materna: a evolução dos conceitos no mundo e no Brasil. In: Galvão L, Díaz, J, organizadores. Saúde sexual e reprodutiva no Brasil: dilema e desafios. São Paulo: Editora Hucitec/ Population Council; 1999. p. 165-79.

9. Goldani AM. O regime demográfico brasileiro nos anos 90: desigualdades, restrições e oportunidades demográficas. In: Galvão L, Díaz, J, organizadores. Saúde sexual e reprodutiva no Brasil: dilema e desafios. São Paulo: Editora Hucitec/Population Council; 1999. p. 25-69.

10. Díaz M, Díaz J. Qualidade da atenção em saúde mental e reprodutiva: estratégias para mudanças. In: Galvão L, Díaz, J, organizadores. Saúde sexual e reprodutiva no Brasil: dilema e desafios. São Paulo: Editora Hucitec/Population Council; 1999. p. 209-33.

11. Ministério da Saúde. Humaniza SUS - Política Nacional de Humanização: documento base para gestores e trabalhadores do SUS. Brasília: Ministério da Saúde; 2004.

12. Instituto Brasileiro de Geografia e Estatística. Indicadores sociais. http://www.ibge.br (acessado em 07/Out/2002).

13. Guiddens A. Mundo em descontrole: o que a globalização está fazendo de nós. $3 \underline{a}$ Ed. Rio de Janeiro: Record; 2003. 
14. Neri AL. Cuidar de idosos no contexto da família: questões psicológicas e sociais. Campinas: Alínea; 2002.

15. Fontana M, Santos SF. Violência contra a mulher. In: Rede Nacional Feminista de Saúde e Direitos Reprodutivos, organizador. Saúde da mulher e direitos reprodutivos: dossiês. São Paulo: Rede Nacional Feminista de Saúde e Direitos Reprodutivos; 2001.

16. Bucher JSNF. Família, locus de vivências: do amor à violência. In: Féres-Carneiro T, organizador. Família e casal: arranjos e demandas contemporâneas. Rio de Janeiro: Editora PUC-Rio/São Paulo: Edições Loyola; 2003. p. 169-83.

17. Diniz G. Condição feminina: fator de risco para a saúde mental? In: Paz MGT, Tamayo A, organizadores. Escola, saúde e trabalho: estudos psicológicos. Brasília: Editora UnB; 1999. p. 181-97.

18. Suárez M, Machado LZ, Bandeira LM. Violência, sexualidade e saúde reprodutiva. In: Galvão L, Díaz, J, organizadores. Saúde sexual e reprodutiva no Brasil: dilema e desafios. São Paulo: Editora Hucitec/Population Council; 1999. p. 277-309.

19. Carvalho IS. Do botão à rosa, da rosa à...: um estudo sobre a queixa depressiva em mulheres na maturidade [Dissertação de Mestrado]. Brasília: Instituto de Psicologia, Universidade de Brasília; 2004.

20. Santos CVM. Climatério e auto-valorização: uma reflexão feminista [Dissertação de Mestrado]. Brasília: Instituto de Psicologia, Universidade de Brasília; 2005.

21. Pondaag MCM. O dito pelo não dito: desafios no trabalho com mulheres vítimas de violência [Dissertação de Mestrado]. Brasília: Instituto de Psicologia, Universidade de Brasília; 2003.

22. Freud S. Tipos de desencadeamento da doença neurótica. v. XI. Rio de Janeiro: Imago Editora; 1976.

23. Jung CG. Tipos psicológicos. v. VI. Petrópolis: Editora Vozes; 1991.

24. Laznic MC. Sexualidade feminina e menopausa. Associação Psicanalítica de Curitiba em Revista 2001; 5: 59-87.

25. Lidz T. A pessoa: seu desenvolvimento durante o ciclo vital. Porto Alegre: Editora Artes Médicas; 1983.

26. Mori ME, Coelho VLD. Mulheres de corpo e alma: aspectos biopsicossociais da mulher de meiaidade. Psicol Reflex Crit 2004; 17:177-87.

27. Trien SF. Menopausa, a grande transformação. O livro completo e definitivo sobre a fase mais silenciosa e mais fecunda da vida da mulher. Rio de Janeiro: Editora Rosa dos Tempos; 1994.

28. Greer G. Mulher: maturidade e mudança. São Paulo: Augustus Editora; 1994.

29. Ramos D. Viva a menopausa naturalmente. São Paulo: Augustus Editora; 1998.
30. Menegon VSM. Menopausa: imaginário social e conversas no cotidiano [Dissertação de Mestrado]. São Paulo: PUC-São Paulo; 1998.

31. Sommer B, Avus N, Meyer P, Ory M, Madden T, Kagawa-Singer M, et al. Attitudes toward menopause and aging across ethnic/racial groups. Psychosom Med 1999; 61:868-75.

32. Campos APM. Tricotando histórias: reflexões sobre uma intervenção psicológica grupal com idosas [Dissertação de Mestrado]. Brasília: Instituto de Psicologia, Universidade de Brasília; 2005.

33. Goldfarb DC. Corpo, tempo e envelhecimento. São Paulo: Casa do Psicólogo; 1998.

34. Diniz G, Coelho V. Mulher, família, identidade: a meia-idade e seus dilemas. In: Féres-Carneiro T, organizador. Família e casal: arranjos e demandas contemporâneas. Rio de Janeiro: Editora PUCRio/São Paulo: Edições Loyola; 2003. p. 79-95.

35. Marracini EM. Mulher: significados no meio da vida [Dissertação de Mestrado]. São Paulo: PUCSão Paulo; 1999.

36. Ciornai S. Da contracultura à menopausa: vivências e mitos da passagem. São Paulo: Oficina de Textos; 1999.

37. Mori ME, Coelho VLD. A vida ou vida: a escuta psicológica e a saúde da mulher de meia-idade. Est Pesqui Psicol 2003; 3:63-78.

38. Portella AP. Novas e velhas questões sobre corpo, sexualidade e reprodução. In: Ávila MBM, organizador. Textos e imagens do feminismo: mulheres construindo a igualdade. Recife: SOS Corpo; 2001. p. 71-131.

39. Ávila MBM, Corrêa S. O movimento de saúde e direitos reprodutivos no Brasil: revisitando percursos. In: Galvão L, Díaz, J, organizadores. Saúde sexual e reprodutiva no Brasil: dilema e desafios. São Paulo: Editora Hucitec/Population Council; 1999. p. 70-103.

40. Formiga Filho JFN. Políticas de saúde reprodutiva no Brasil: uma análise do PAISM. In: Galvão L, Díaz J, organizadores. Saúde sexual e reprodutiva no Brasil: dilema e desafios. São Paulo: Editora Hucitec/Population Council; 1999. p. 151-62.

41. Ministério da Saúde. Política Nacional de Atenção Integral à Saúde da Mulher: plano de ação 2004-2007. Brasília: Ministério da Saúde; 2004.

42. Seidl EMF, Costa Jr. AL. O psicólogo na rede pública de saúde do Distrito Federal. Psicol Teor Pesqui 1999; 15:27-35.

43. Coelho V, Diniz G. Vida de mulher: lidando com a meia-idade e a menopausa. In: Féres-Carneiro T, organizador. Família e casal: arranjos e demandas contemporâneas. Rio de Janeiro: Editora PUCRio/São Paulo: Edições Loyola; 2003. p. 97-117.

Recebido em 26/Abr/2005

Versão final reapresentada em 27/Set/2005 Aprovado em 03/Jan/2006 